\title{
ANALYTICAL AND FINITE ELEMENT BUCKLING AND POST BUCKLING ANALYSIS OF LAMINATED PLATES
}

\section{R S Gowda, Prashant Sunagar, Nruthya K, Abhishek Kumar Chaurasiya and Priyanka}

Department of Civil Engineering, M S Ramaiah Institute of Technology, Bangalore, Karnataka, India

Manish S Dharek

Department of Civil Engineering, BMS Institute of Technology and Management, Bengaluru, India

\section{Sreekeshava K S}

Department of Civil Engineering, Jyothy Institute of Technology, Bengaluru, India

\begin{abstract}
This examination is engaged into assessing the clasping heap of isotropic and overlaid plates $\left(15^{\circ} / 30^{\circ} / 45^{\circ} / 60^{\circ}\right)$ which is exposed to in plane pressure. The investigation device utilized for this intention was ANSYS 19.0. The clasping load is assessed by changing the parameters, for example, angle proportion $(a / b)$, thickness proportion $(S)$ and limit conditions. It was noticed that diverse length to broadness proportion influenced the basic clasping load and the fiber direction edges likewise influenced the basic clasping load symmetric point employ plates.
\end{abstract}

Keywords: Buckling Analysis, Post-Buckling Analysis, Laminated Plates, Fibre Reinforced Polymers.

Cite this Article: R S Gowda, Prashant Sunagar, Nruthya K, Manish S Dharek, Sreekeshava K S, Abhishek Kumar Chaurasiya and Priyanka, Analytical and Finite Element Buckling and Post Buckling Analysis of Laminated Plates. International Journal of Civil Engineering and Technology, 11(5), 2020, pp. 84-92.

https://iaeme.com/Home/issue/IJCIET?Volume=11\&Issue=5

\section{INTRODUCTION}

Composite overlaid structures are commonly used today because of the positive properties, for example, their tolerably high caliber to-weight extent and insurance from consumption. Subsequently, the utilization of overlaid composite structures is turning out to be increasingly well known. A crucial issue is their delicate quality in the through-the-thickness bearing, for the most part because of their innate low grip interlinear quality. In many building structures, for example, segments, shafts, or plates, their disappointment creates from extreme worries as well as from buckling. just square flimsy plates are considered in the current investigation. At 
the point when a level plate is exposed to low in-plane compressive burdens, it stays level and is in balance condition. As the size of the in-plane pressure load increments, be that as it may, the harmony setup of the plate is inevitably changed to a non-level design and the plate winds up unreliable. The size of the compressive burden at which the plate becomes precarious is known as the "basic buckling load."

A composite material involves at any rate two materials and offers a basic weight sparing in structures in context of its high caliber to weight and high solidness to weight degrees. Further, in a fiber composite, the mechanical properties can be wavered as required by fittingly masterminding the direction the strands. In such material the fibers are the standard burden bearing people, and the lattice, which has low modulus and high expanding, gives the basic versatility and in addition keeps the filaments in position and shield them from the earth.

Composite materials can't avoid being materials with at any rate two constituents solidified to shape a material with unexpected properties in comparison to those of the individual constituents. Fiber fortified plastic (FRP) is a composite material that contains two constituents: a progression of strands encompassed by framework. A layer of composite material is described as a lamina and stacking lamina outlines a FRP cover. FRP has been used for quite a while in the aviation and car businesses and has as of late been utilized in structural designing structures as a choice to steel, wood, and cement.

The underlying hypothetical examination into versatile flexural-torsional buckling was gone before by Euler's (1759) treatise on area flexural buckling, which gave the fundamental explanatory strategy for foreseeing the diminished characteristics of slim sections, and by Holy person Venart's 1855 journal on uniform torsion, which gave the essential strong depiction of the turning response of people to torsion. Chen and Bert (1976) investigated ideal plan of basically bolstered rectangular plates overlaid to composite material and exposed to uniaxial compressive stacking. Numerical results are presented for ideal structure plates overlaid of glass/epoxy, boron/epoxy, and carbon/epoxy composite materials. Covered plates with strip-type delamination under twisting were examined logically and probably by Yeh and Tooth (1997). Radu and Chattopadhyay (2000) used a refined higher request shear twisting hypothesis to break down the dynamic precariousness related with composite plates with delamination that at risk to dynamic compressive burdens. Hwang and Mao (2oo1) directed the non-straight buckling and post-buckling assessments to foresee the delamination buckling burden and delamination development load. A powerful examination exhibit is proposed by Wen-pie and Lin Cheng (2oo3) to acquire buckling heap of plate. Wang and Lu (2oo3) finished an assessment to examination the buckling conduct of neighborhood delamination close to the outside of fiber strengthened overlaid plates under mechanical and warm loads. Shukla and Kreuzer (20o5) proposed a detailing dependent on the main request shear twisting speculation and von-Karman-type nonlinearity to gauges the basic/buckling heaps of covered composite rectangular plates under in-plane uniaxial and biaxial loadings. Pankok and Singhatanadgid (2006) learns about the buckling conduct of rectangular and slant dainty composite plates with various boundary conditions using the Ritz system close by the proposed out-of-plane boundary conditions.

Buket okutan Baba (2007) considered the effect of boundary conditions on the buckling load for rectangular plates. Pein and Zahari (2007) inspected the basic conduct of woven texture composites subject to compressive burden which is deficient. A dynamic disappointment examination figuring has been created by Zahari and Azmee (20o8) and executed as a client subroutine in a limited component code (ABAQUS) so as to demonstrate the non-straight material conduct and to catch the total compressive reaction of woven composite plates made of glass-epoxy material. 
The current examination is done to dissect the impact on buckling and post buckling conduct with various boundary condition, perspective proportion, thickness and employ direction. The buckling conduct of plates ought to be researched appropriately as these plates may have dismembered for different boundary condition. In this way the examination is fundamental with a particular ultimate objective to know the buckling conduct of such plates.

\section{PROBLEM STATEMENT}

ANSYS is utilized to dissect the basic buckling heap of different overlaid plates so as to perceive how changes in the covered plate would have influence the buckling load. The progressions to the covered plate depended on four factors: thickness, boundary condition, viewpoint proportion and direction of the sewed tangle layers utilized in FRP. The covered plates were broke down under a boundary condition: Essentially just basically. The boundary condition was applied to the edge hubs of the plate in a similar way as was accomplished for the isotropic plates and will find in the demonstrating area. Three unmistakable plate thicknesses were used: $8 \mathrm{~mm}, 1 \mathrm{omm}$, and $12 \mathrm{~mm}$. Four distinctive angle proportions $(\mathrm{a} / \mathrm{b})$ were seen as: $1,1.25,1.5$, and 2.o. The length, a, was held steady at 1 looomm and the width, b, is fluctuated b/w 1ooomm, 80omm, 666.667mm and 5oomm.

Table 1 Longitudinal and transverse modulus of laminated plates for different orientation:

\begin{tabular}{|l|c|c|c|c|}
\hline & $\mathbf{1 5}$ & $\mathbf{3 0}$ & $\mathbf{4 5}$ & $\mathbf{6 0}$ \\
\hline Ex (Mpa) & 23595 & 20685.28 & 18037.69 & 16934.52 \\
\hline Ey (Mpa) & 10902 & 11087.77 & 12342.62 & 14969.52 \\
\hline Poison's ratio & 0.25 & 0.25 & 0.25 & 0.25 \\
\hline $\begin{array}{l}\text { Shear modulus, } \\
\text { Gx (Mpa) }\end{array}$ & $414 \mathrm{o}$ & $414 \mathrm{o}$ & $414 \mathrm{o}$ & $414 \mathrm{o}$ \\
\hline $\begin{array}{l}\text { Shear modulus, } \\
\text { Gy (Mpa) }\end{array}$ & $345 \mathrm{o}$ & 3450 & $345 \mathrm{o}$ & 3450 \\
\hline
\end{tabular}

\subsection{Bending stiffness for $(+15 /-15 /-15 /+15)$ orientation}

Table 2 Bending Stiffness Matrix D Mpa

\begin{tabular}{|c|c|c|c|c|}
\hline $\begin{array}{c}\text { Plates } \\
\text { thickness } \\
(\mathrm{mm})\end{array}$ & $\mathbf{D}_{\mathbf{1 1}}$ & $\mathbf{D}_{\mathbf{2 2}}$ & $\mathbf{D}_{\mathbf{6 6}}$ & $\mathbf{D}_{\mathbf{1 2}}$ \\
\hline 8 & 1073796 & 496120.3559 & $1472 \mathrm{o} 1.15$ & $124 \mathrm{o} 31.11 \mathrm{o3}$ \\
\hline 10 & 2097159 & 968938.7409 & 287489.5 & 242235.7269 \\
\hline 12 & 3624034 & 1674394.12 & 496800 & 418599.352 \\
\hline
\end{tabular}


R S Gowda, Prashant Sunagar, Nruthya K, Manish S Dharek, Sreekeshava K S,

Abhishek Kumar Chaurasiya and Priyanka

\subsection{Bending stiffness for $(+30 /-30 /-3 o /+3 o)$ orientation}

Table 3 Bending Stiffness Matrix D Mpa

\begin{tabular}{|c|c|c|c|c|}
\hline $\begin{array}{c}\text { Plates } \\
\text { thickness } \\
(\mathrm{mm})\end{array}$ & $\mathbf{D}_{\mathbf{1 1}}$ & $\mathbf{D}_{\mathbf{2 2}}$ & $\mathbf{D}_{\mathbf{6 6}}$ & $\mathbf{D}_{\mathbf{1 2}}$ \\
\hline 8 & 941371.9 & 504575.822 & $1472 \mathrm{o} 1.15$ & $126143.79 \mathrm{o} 8$ \\
\hline 10 & 1838528 & 985451.5804 & 287488.5 & 246363.8118 \\
\hline 12 & $31771 \mathrm{o} 5$ & 1702927.72 & $4968 \mathrm{o} 1$ & 425731.968 \\
\hline
\end{tabular}

\subsection{Bending stiffness for $(45 /-45 /-45 / 45)$ orientation}

Table 4 Bending Stiffness Matrix [D] Mpa

\begin{tabular}{|c|c|c|c|c|}
\hline $\begin{array}{c}\text { Plate thickness } \\
(\mathrm{mm})\end{array}$ & $\mathbf{D}_{\mathbf{1 1}}$ & $\mathbf{D}_{\mathbf{2 2}}$ & $\mathbf{D}_{\mathbf{6 6}}$ & $\mathbf{D}_{\mathbf{1 2}}$ \\
\hline 8 & 820877.2 & 561685.0281 & $1472 \mathrm{o} 1.15$ & 140430.937 \\
\hline 10 & 1603197 & 1096989.619 & 287488.5 & 274247.5297 \\
\hline 12 & 2770436 & 1895673.16 & 496801 & 473917.96 \\
\hline
\end{tabular}

\subsection{Bending stiffness for $(60 /-60 /-60 / 60)$ orientation}

Table 5 Bending Stiffness Matrix [D] Mpa

\begin{tabular}{|c|c|c|c|c|}
\hline $\begin{array}{c}\text { Plates } \\
\text { thickness } \\
(\mathrm{mm})\end{array}$ & $\mathbf{D}_{\mathbf{1 1}}$ & $\mathbf{D}_{\mathbf{2 2}}$ & $\mathbf{D}_{\mathbf{6 6}}$ & $\mathbf{D}_{\mathbf{1 2}}$ \\
\hline 8 & 770669.3 & 579827.1832 & $1472 \mathrm{o} 2.15$ & 154621.088 \\
\hline 10 & 1505142 & 1132419.868 & 287488.5 & 301978.9204 \\
\hline 12 & 2600989 & 1956899.08 & $4968 \mathrm{o} 1$ & 521839.72 \\
\hline
\end{tabular}

\section{RESULTS}

The present examination presents aftereffects of limited component investigation of composite covered plates. The limited component model utilized is the discrete model methodology. The limited component program (ANSYS) was utilized to consider the reproduced conduct of the plates and contrasted and hypothetical definition. Program ANSYS is fit for taking care of devoted numerical models for buckling conduct of composite covered plate under static. Eight-hub strong block components (Shell 281) were utilized to display the composite overlaid plate. SHELL281 is appropriate for dissecting flimsy to decently thick shell structures. The component has eight hubs with six degrees of opportunity at every hub: 
interpretations in the $\mathrm{x}, \mathrm{y}$, and $\mathrm{z}$ tomahawks, and pivots about the $\mathrm{x}, \mathrm{y}$, and $\mathrm{z}$-tomahawks. (When utilizing the film choice, the component has translational degrees of opportunity just.) SHELL281 is appropriate for straight, enormous revolution, as well as huge strain nonlinear applications. Change in shell thickness is represented in nonlinear investigations. The component represents devotee (load firmness) impacts of disseminated pressures. SHELL281 might be utilized for layered applications for demonstrating composite shells or sandwich development. The precision in displaying composite shells is administered by the principal request shear-twisting hypothesis (as a rule alluded to as Mindlin-Reissner shell hypothesis). The component definition depends on logarithmic strain and genuine pressure measures. The component kinematics take into consideration limited layer strains (extending). Notwithstanding, the arch changes inside a period addition are thought to be little.

\subsection{Critical Buckling Load for Isotropic Plates}

Simply-Simply-Simply-Simply

Table 6

\begin{tabular}{|c|c|c|c|c|c|c|}
\hline $\begin{array}{c}\text { Length (a) } \\
\text { in } \mathbf{~ m m}\end{array}$ & $\begin{array}{c}\text { Breadth } \\
\text { (b) in } \mathbf{~ m m}\end{array}$ & $\begin{array}{c}\text { Aspect ratio } \\
(\mathbf{a} / \mathbf{b})\end{array}$ & $\begin{array}{c}\text { Thickness } \\
\text { in } \mathbf{~ m m}\end{array}$ & $\begin{array}{c}\text { Calculated } \\
\text { critical } \\
\text { buckling } \\
\text { load N/mm }\end{array}$ & $\begin{array}{c}\text { ANSYS } \\
\text { critical } \\
\text { buckling } \\
\text { load N/mm }\end{array}$ & $\begin{array}{c}\text { Percentage } \\
\text { difference }\end{array}$ \\
\hline 4000 & 1000 & 1 & 8 & 370.196 & 368.42 & $0.48 \%$ \\
\hline 4000 & 1000 & 1 & 10 & 723.047 & 718.63 & $0.61 \%$ \\
\hline 4000 & 1000 & 1 & 12 & 1249.41 & 1240.12 & $0.74 \%$ \\
\hline
\end{tabular}

\subsection{Critical buckling load for laminated plate $(15 /-15 /-15 / 15)$} Simply-Simply-Simply-Simply

Table 7

\begin{tabular}{|c|c|c|c|c|c|c|}
\hline $\begin{array}{l}\mathbf{A} \text { in } \\
\mathbf{~ m m}\end{array}$ & B in mm & $\begin{array}{c}\text { Aspect } \\
\text { ratio } \\
(\mathbf{a} / \mathbf{b})\end{array}$ & $\begin{array}{c}\text { Plate thickness } \\
\text { in } \mathbf{~ m m}\end{array}$ & $\begin{array}{c}\text { Calculated } \\
\text { critical } \\
\text { buckling load } \\
\text { in Mpa }\end{array}$ & $\begin{array}{c}\text { ANSYS } \\
\text { critical } \\
\text { buckling } \\
\text { load in } \\
\text { Mpa }\end{array}$ & Percentage error \\
\hline 1000 & 1000 & 1 & 8 & 23.74 & 25.20 & $6.14 \%$ \\
\hline 1000 & 800 & 1.25 & 8 & 34.512 & 38.25 & $10.83 \%$ \\
\hline 1000 & 666.667 & 1.5 & 8 & 53.94 & 58.27 & $10.1 \%$ \\
\hline 1000 & 500 & 2 & 8 & 94.512 & 100.51 & $6.21 \%$ \\
\hline 1000 & 1000 & 1 & 10 & 46.38 & 49.11 & $6.35 \%$ \\
\hline 1000 & 800 & 1.25 & 10 & 67.40 & 74.52 & $6.45 \%$ \\
\hline 1000 & 666.667 & 1.5 & 10 & 105.36 & 113.48 & $6.84 \%$ \\
\hline 1000 & 500 & 2 & 10 & 185.55 & 195.48 & $5.35 \%$ \\
\hline 1000 & 1000 & 1 & 12 & 80.143 & 84.66 & $5.62 \%$ \\
\hline 1000 & 800 & 1.25 & 12 & 116.45 & 128.41 & $10.31 \%$ \\
\hline 1000 & 666.667 & 1.5 & 12 & 182.07 & 195.53 & $7.14 \%$ \\
\hline 1000 & 500 & 2 & 12 & 320.64 & 336.28 & $4.9 \%$ \\
\hline
\end{tabular}


R S Gowda, Prashant Sunagar, Nruthya K, Manish S Dharek, Sreekeshava K S,

Abhishek Kumar Chaurasiya and Priyanka

\subsection{Critical buckling load for laminated plate (3o/-3o/-3o/3o)}

Simply-Simply-Simply-Simply

Table 8

\begin{tabular}{|c|c|c|c|c|c|c|}
\hline A in $\mathbf{~ m m}$ & B in $\mathbf{~ m m}$ & $\begin{array}{c}\text { Aspect } \\
\text { ratio } \\
\text { (a/b) }\end{array}$ & $\begin{array}{c}\text { Plate thickness } \\
\text { in } \mathbf{~ m m ~}\end{array}$ & $\begin{array}{c}\text { Calculated } \\
\text { critical buckling } \\
\text { load in Mpa }\end{array}$ & $\begin{array}{c}\text { ANSYS critical } \\
\text { buckling load in } \\
\text { Mpa }\end{array}$ & $\begin{array}{c}\text { Percentage } \\
\text { error }\end{array}$ \\
\hline 1000 & 1000 & 1 & 8 & 23.12 & 25.53 & $10.21 \%$ \\
\hline 1000 & 800 & 1.25 & 8 & 36.52 & 40.32 & $10.91 \%$ \\
\hline 1000 & 666.667 & 1.5 & 8 & 57.45 & 62.54 & $8.7 \%$ \\
\hline 1000 & 500 & 2 & 8 & 96.87 & 101.89 & $5.12 \%$ \\
\hline & & & & & & \\
\hline 1000 & 1000 & 1 & 10 & 47.23 & 50.21 & $6.38 \%$ \\
\hline 1000 & 800 & 1.25 & 10 & 72.94 & 78.24 & $8.3 \%$ \\
\hline 1000 & 666.667 & 1.5 & 10 & 115.65 & 123.99 & $6.92 \%$ \\
\hline 1000 & 500 & 2 & 10 & 185.54 & 198.103 & 7.02 \\
\hline & & & & & & \\
\hline 1000 & 1000 & 1 & 12 & 83.84 & 86.56 & $3.21 \%$ \\
\hline 1000 & 800 & 1.25 & 12 & 125.45 & 135.31 & $8.01 \%$ \\
\hline 1000 & 666.667 & 1.5 & 12 & 198.12 & 209.79 & $5.54 \%$ \\
\hline 1000 & 500 & 2 & 12 & 324.56 & 340.69 & $4.98 \%$ \\
\hline
\end{tabular}

\subsection{Critical buckling load for laminated plate $(45 /-45 /-45 / 45)$}

Simply-Simply-Simply-Simply

Table 9

\begin{tabular}{|c|c|c|c|c|c|c|}
\hline A in mm & B in mm & $\begin{array}{c}\text { Aspect } \\
\text { ratio } \\
(\mathbf{a} / \mathbf{b})\end{array}$ & $\begin{array}{c}\text { Plate } \\
\text { thickness in } \\
\mathbf{m m}\end{array}$ & $\begin{array}{c}\text { Calculated } \\
\text { critical buckling } \\
\text { load in Mpa }\end{array}$ & $\begin{array}{c}\text { ANSYS } \\
\text { critical } \\
\text { buckling load } \\
\text { in Mpa }\end{array}$ & $\begin{array}{c}\text { Percentage } \\
\text { error }\end{array}$ \\
\hline 1000 & 1000 & 1 & 8 & 26.23 & 26.23 & $6.14 \%$ \\
\hline 1000 & 800 & 1.25 & 8 & 42.70 & $42.7 \mathrm{o}$ & $10.83 \%$ \\
\hline 1000 & 666.667 & 1.5 & 8 & 63.02 & 63.02 & $10.1 \%$ \\
\hline 1000 & 500 & 2 & 8 & 103.96 & 103.96 & $6.21 \%$ \\
\hline & & & & & & \\
\hline 1000 & 1000 & 1 & 10 & 51.02 & 51.02 & $6.35 \%$ \\
\hline 1000 & 800 & 1.25 & 10 & 78.44 & 83.12 & $6.45 \%$ \\
\hline 1000 & 666.667 & 1.5 & 10 & 114.52 & 122.56 & $6.84 \%$ \\
\hline 1000 & 500 & 2 & 10 & 192.63 & 201.94 & $5.35 \%$ \\
\hline & & & & & & \\
\hline 1000 & 1000 & 1 & 12 & 83.26 & 87.88 & $5.62 \%$ \\
\hline 1000 & 800 & 1.25 & 12 & 133.54 & 143.2 & $10.31 \%$ \\
\hline 1000 & 666.667 & 1.5 & 12 & 202.16 & 210.86 & $7.14 \%$ \\
\hline 1000 & 500 & 2 & 12 & 330.26 & 346.96 & $5.12 \%$ \\
\hline
\end{tabular}




\subsection{Critical buckling load for laminated plate (6o/-6o/-6o/6o) Simply-Simply-Simply-Simply}

Table 10

\begin{tabular}{|c|c|c|c|c|c|c|}
\hline A in mm & B in mm & $\begin{array}{c}\text { Aspect } \\
\text { ratio } \\
(\mathbf{a} / \mathbf{b})\end{array}$ & $\begin{array}{c}\text { Plate } \\
\text { thickness in } \\
\mathbf{m m}\end{array}$ & $\begin{array}{c}\text { Calculated } \\
\text { critical buckling } \\
\text { load in Mpa }\end{array}$ & $\begin{array}{c}\text { ANSYS } \\
\text { critical } \\
\text { buckling } \\
\text { load in Mpa }\end{array}$ & $\begin{array}{c}\text { Percentage } \\
\text { error }\end{array}$ \\
\hline 1000 & 1000 & 1 & 8 & 21.95 & 24.84 & $9.84 \%$ \\
\hline 1000 & 800 & 1.25 & 8 & 38.12 & 42.74 & $10.1 \%$ \\
\hline 1000 & 666.667 & 1.5 & 8 & 56.78 & 61.53 & $8.7 \%$ \\
\hline 1000 & 500 & 2 & 8 & 97.24 & 102.49 & $5.12 \%$ \\
\hline & & & & & & \\
\hline 1000 & 1000 & 1 & 10 & 47.24 & 50.33 & $6.31 \%$ \\
\hline 1000 & 800 & 1.25 & 10 & 76.61 & 83.24 & $8.31 \%$ \\
\hline 1000 & 666.667 & 1.5 & 10 & 111.95 & 119.74 & $6.92 \%$ \\
\hline 1000 & 500 & 2 & 10 & 186.32 & 199.22 & $7.02 \%$ \\
\hline & & & & & & \\
\hline 1000 & 1000 & 1 & 12 & 84.23 & 86.74 & $2.97 \%$ \\
\hline 1000 & 800 & 1.25 & 12 & 132.95 & 143.41 & $8.01 \%$ \\
\hline 1000 & 666.667 & 1.5 & 12 & 196.79 & 206.09 & $4.54 \%$ \\
\hline 1000 & 500 & 2 & 12 & 329.86 & 342.50 & $3.98 \%$ \\
\hline
\end{tabular}

Load vs displacement curve for loading edge simply supported and unloaded edge simply supported

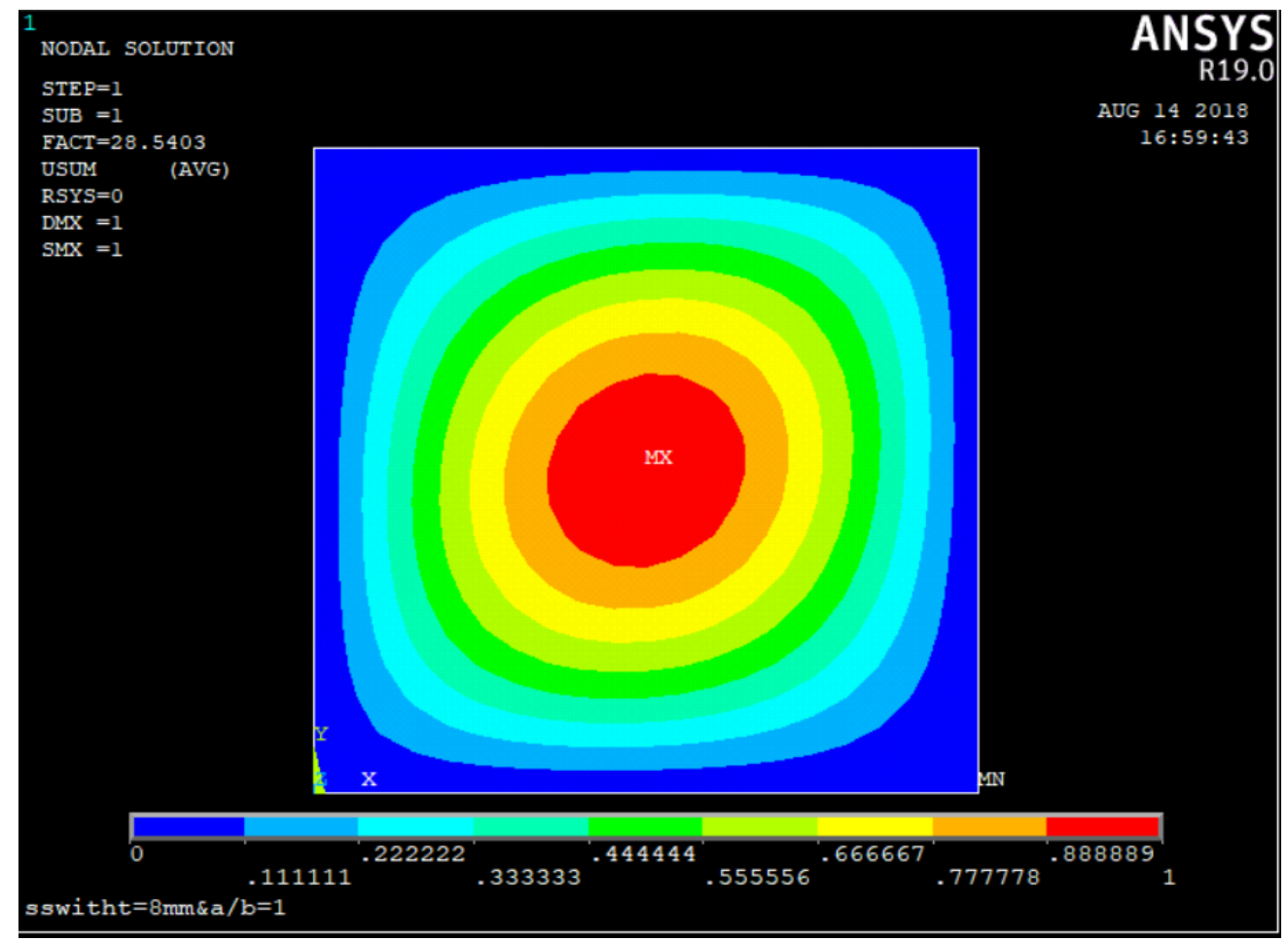

Figure 1 Ply orientation $( \pm 45)_{2}, t=8 \mathrm{~mm}$, aspect ratio $(\mathrm{a} / \mathrm{b})=1$ 
R S Gowda, Prashant Sunagar, Nruthya K, Manish S Dharek, Sreekeshava K S,

Abhishek Kumar Chaurasiya and Priyanka

\section{CONCLUSION}

This investigation considers the buckling reaction of overlaid rectangular plates with various boundary conditions. The overlaid composite plates have changing thickness, direction and viewpoint proportion. From the present systematic, the accompanying ends can be made.

1. It was noticed that diverse length to expansiveness proportion influenced the basic buckling load. The buckling load increments as the a/b proportion increments. At the point when the perspective proportion changed from 0.5 to 1 , the variety in buckling load is practically $24 \%$. The pace of progress of buckling load with the angle proportion is practically uniform.

2. It was seen that the distinctive fiber direction edges influenced the basic buckling load symmetric point employ plates. The plate with $[[ \pm 45]] \_4$ layup has the most noteworthy buckling load and the plate with [ \pm 60$]$ layup has the least buckling load for all sides just bolstered condition. Be that as it may, this isn't the situation for the other four boundary conditions, where it appears the best decision would be $(+15 /-15)$ for viewpoint proportions under 2.0.

3. It is obvious from the examination that the there is a correspondence between the traditional investigation and Limited Component Examination. Its element physical noteworthiness recommends that the demonstrating of plates as the cases for overlaid plates can be conceivable in ANSYS.

4. Hypothetical benefits of buckling load for overlaid plates utilizing Traditional cover hypothesis (CLT) are coordinating with expository qualities for all side essentially upheld condition. The normal level of mistake is less $5 \%$.

\section{REFERENCES}

[1] A K Sreevastva, R.K Singh. Effect of aspect ratio on buckling of composite plates-. Journal of Composites Science and Technology 59 (1999) 439-445

[2] Buket Okutan Baba and Aysun Baltaci. Buckling characteristics of symmetrically and anti-symmetrically laminated composite plates with central cutout,- Applayed Composite Materials - 14 (2007):265-276

[3] C.W. Pein and R. Zahari. Experimental investigation of the damage behaviour of woven fabric glass/epoxy laminated plates with circular cut-outs subjected to compressive force,International Journal of Engineering and Technology, (2oo7)Vol. 4, No. 2, pp.26o-265

[4] Chavanan supasak, A comparison of experimental buckling load of rectangular plates determined from various measurement method-.Department of mechanical engineering,Bangok,(2oo6)18-2o,2547

[5] Chainarin Pannok and Pairod Singhatanadgid. Buckling analysis of composite laminate rectangular and skew plates with various edge support conditions. - The 2oth Conference of Mechanical Engineering Network of Thailand (2oo6)18-2o.

[6] David Roylance, Laminated composite plates, Massachusetts Institute of Technology Cambridge, (200o) MA o2139.

[7] D. Bucco and J. Mazumdar, Buckling analysis of plates of arbitrary shape, journal of Austral. Math. Soc. Ser. B 26 (1984), 77-91

[8] E. A. Pieczyska, R. B. PecherskI and S.P. Gadaj. Experimental and theoretical investigations of glass-fibre reinforced composite subjected to uniaxial compression for a wide spectrum of strain rates. Arch. Mech., 58 (2006), 3, pp. 273-291.

[9] G. Garya and H. Zhao. Dynamic testing of fibre polymer matrix composite plates under in-plane compression- Journal of Composites: Part A 31 (20oo) 835-84o. 
[10] Ionel Chirica, Elena-Felicia and R. Chirica. Numerical tests on the buckling of the plates made of composite materials, Romanian technical sciences academy, vol.3(20o6)

[11] John Tomblin \& Ever Barbero, Local buckling experiments on FRP Columns, Journal of Thin-Walled Structures 18 (1994) 97-116.

[12] K. K. Shukla; Y. Nath; E. Kreuzer; and K. V. Sateesh Kumar. Buckling of Laminated Composite Rectangular Plates, Journal of aerospace engineering, vol.18(20o5):215.

[13] K. M. Jeong and H. G. Beom, Buckling Analysis of an Orthotropic Layer Bonded to a Substrate with an Interface Crack, Journal of composite materials, Vol. 37, No. 18(2oo3).

[14] M. Kamruzzaman, A. Umar and S. Q. A. Naqvi. Effect of composite type and its configuration on buckling strength of thin laminated composite plates, Latin American Journal of Solids and Structures 3 (20o6) 279-299.

[15] M.R. Bambach, Local buckling and post-local buckling redistribution of stress in slender plates and sections, Journal of Thin-Walled Structures 44 (20o6) 1118-1128.

[16] M.R. Khalili, K. Malekzadeh, R.K. Mittal, A new approach to static and dynamic analysis of composite plates with different boundary conditions, Journal of Composite Structures 69 (2005) 149-155.

[17] M. Darvizeh, A. Darvizeh, R. Ansari and C.B. Sharma. Buckling analysis of generally laminated composite plates- journal of composite structures,vol.63(20o4), pages 69-74.

[18] Murat Yazic, Buckling of Square Perforated Thermoplastic Composite Plates, Journal of Reinforced Plastics and Composites (2008) 27; 1059.

[19] N G R Iyengar. Structural stability of columns and plates, EWP pvt. Ltd.

[20] Qing-Qing Ni, Jia Xie and Masaharu Iwamoto, Buckling analysis of laminated composite plates with arbitrary edge supports, Composite Structures 69 (2005) 209-217.

[21] Stephen p. Timoshenko and Kriger - Theory of plates and shells-McGraw-Hill International editions. 